\title{
THE CALCULATION OF PIPELINE NETWORK COMPRISING PRESSURE REDUCTION VALVE (PRV) WITH Q-EQUATION
}

\author{
Alexandru Ioan \\ University "Dunarea de Jos" of Galati, \\ Faculty of Naval Architecture, Galati, Domneasca \\ Street, No. 47, 800008, Romania, \\ E-mail:Ioan.Alexandru@ugal.ro
}

\begin{abstract}
The calculation of pipeline networks with $Q$ - equations involves the determination of flow rates of liquid flowing through pipes by solving the system of equations comprising the mass conservation equation and the energy conservation equations written along the loops and pseudo-loops. The paper presents an application that solves a network comprising a PRV (Pressure reduction valve). In case of mounting a PRV in the device it takes place a leap of energy and energy conservation equation along a loop is no longer valid. The literature recommends fitting a fictitious tank instead of the device and writing the energy conservation equation in the pseudo-loop.
\end{abstract}

Keywords: solution, Newton-Raphson, network, system, loop, node.

\section{THE PRESENTATION OF Q- EQUATIONS METHOD FOR SOLVING PIPE NETWORK}

The Calculation of a pipeline network with Q-equations involves calculating pipe flows under stationary flow conditions when the pipe properties (L-length, Ddiameter, material type and k-roughness) are known. The system of Q-equations contains the continuity equations in the nodes (Ec.1) and the equation of energy conservation written along the loops (Ec.2) and the pseudo-loops (Ec.3).

$$
\sum_{k=1}^{r} Q_{j k}-\sum_{i=1}^{m} Q_{j i}=0
$$

where:

$\mathrm{j}$-junction number (node),

$\mathrm{Q}_{\mathrm{k}}$-imposed flow in the pipe $\mathrm{k}$,
$\mathrm{Q}_{\mathrm{i}}$-flow on pipe $\mathrm{i}$, r-number of flow imposed,

m-number of flow pipe connected to node $\mathrm{j}$.

A loop is considered a sequence of pipes that begins in a node and ends in the same node. For a loop, the energy conservation equation is written as (Ec.2).

$$
\sum_{i=1}^{n} h_{f i}=0
$$

where:

$$
\mathrm{h}_{\mathrm{fi}} \text {-head loss on pipe } \mathrm{i} \text {, }
$$
n-number of head losses.

A pseudo-loop is a sequence of pipes where the heads to the ends load is known. The energy equation for a pseudo-loop has the form of (Ec.3). 


$$
H_{L}-H_{R}=\sum_{i=1}^{n} h_{f i}
$$

where:

$\mathrm{h}_{\mathrm{fi}}$-head loss on the pipe,

n-number of head loss,

$\mathrm{H}_{\mathrm{L}}$-head in the left end of pseudo loop,

$\mathrm{H}_{\mathrm{R}}$-head in the right end of pseudo loop.

In (Fig.1) is represented a network that comprises a loop and a pseudo-loop. The energy conservation equation is written along the loop and pseudo-loop.

For loop I, the energy conservation equation, considering clockwise the positive sense, has the form:

$$
\begin{aligned}
& H_{B}=h_{f B C}+h_{f C E}-h_{f E B}+H_{B} \rightarrow \\
& \rightarrow h_{f B C}+h_{f C E}-h_{f E B}=0
\end{aligned}
$$

where:

$\mathrm{H}_{\mathrm{B}}$-energy head at node $\mathrm{B}$,

$\mathrm{h}_{\mathrm{fBC}}-$ head loss on the pipe $\mathrm{BC}$,

$\mathrm{h}_{\mathrm{fCE}}$ - head loss on the pipe CE,

$\mathrm{h}_{\mathrm{fEB}}$ - head loss on the pipe EB.

The head loss $\mathrm{h}_{\mathrm{fEB}}$ has minus sign because the flow is counter clockwise.

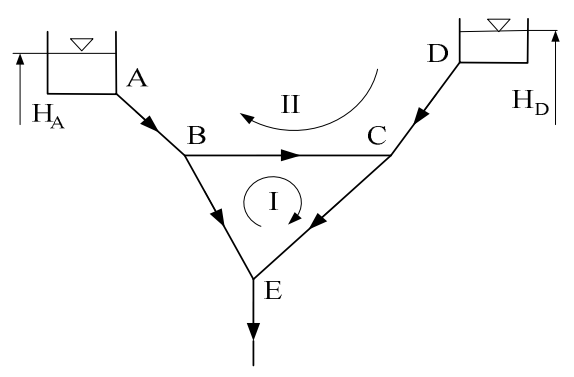

Fig.1 The network containing a loop and a pseudo-loop

In the case of pseudo loop II, the energy conservation equation has the form:

$$
H_{D}-H_{A}=h_{f C D}-h_{f C B}-h_{f B A}
$$

where:

$\mathrm{H}_{\mathrm{D}^{-}}$elevation of liquid level in the tank $\mathrm{D}$, $\mathrm{H}_{\mathrm{A}}$ - elevation of liquid level in the tank $\mathrm{A}$, $\mathrm{h}_{\mathrm{fCD}}$ - head loss on the pipe $\mathrm{CD}$, $\mathrm{h}_{\mathrm{fCB}}$ - head loss on the pipe $\mathrm{CB}$, $\mathrm{h}_{\mathrm{fEA}}$ - head loss on the pipe EA.

The head losses $\mathrm{h}_{\mathrm{fCB}}$ and $\mathrm{h}_{\mathrm{fCA}}$ have minus sign because the flow is counter clockwise. Head losses are expressed in relation to flow rates by

$$
h_{f i j}=H_{i}-H_{j}=a_{i j} \cdot Q_{i j}^{n}
$$

where:

$\mathrm{H}_{\mathrm{i}}$-energy head in junction $\mathrm{i}$ of pipe,

$\mathrm{H}_{\mathrm{j}}$-energy head in junction $\mathrm{j}$ of pipe,

n-exponent,

aij-hydrodynamic coefficient.

The hydrodynamic coefficient aij is calculated with the relationship (5) [1].

$$
a_{i j}=\left[\left(f_{i j} \cdot \frac{L_{i j}}{D_{i j}}+\sum_{1}^{m} \varsigma_{k}\right) \frac{8}{2 \cdot g \cdot \pi^{2} \cdot D_{i j}^{4}}\right]
$$

where:
$\mathrm{f}_{\mathrm{ij}}$-friction coefficient,
$\mathrm{L}_{\mathrm{ij}}$-length of pipe between nodes $\mathrm{i}$ and $\mathrm{j}$,
$\mathrm{D}_{\mathrm{ij}}$-pipe diameter between nodes $\mathrm{i}$ and $\mathrm{j}$, $\zeta_{\mathrm{k}}$-local head loss, g-gravitational acceleration.

The system of equations (2), (3), (4) relative (2), (4), (5) is solved with the iterative Newton-Raphson method.

The equations of mass conservation in junctions and the energy conservation equations in loops and pseudo-loops are considered as:

$$
\begin{aligned}
& F_{1}\left(x_{1}, x_{2}, \ldots, x_{n}\right)=0 \\
& F_{2}\left(x_{1}, x_{2}, \ldots, x_{n}\right)=0
\end{aligned}
$$




$$
\begin{aligned}
& F_{3}\left(x_{1}, x_{2}, \ldots, x_{n}\right)=0 \\
& F_{n}\left(x_{1}, x_{2}, \ldots, x_{n}\right)=0
\end{aligned}
$$

where unknown $\mathrm{x}_{1}, \mathrm{x}_{2}, \ldots \mathrm{x}_{\mathrm{n}}$ are flow rates $\mathrm{Q}_{1}, \mathrm{Q}_{2}, \ldots \mathrm{Q}_{\mathrm{n}}$, in this case.

The iterative formula Newton-Raphson for solving the equation system is:

$$
\{x\}^{(m+1)}=\{x\}^{(m)}-[J]^{-1}\{F\}^{(m)}
$$

where:

$\{x\}^{(m+1)}$-vector of unknowns at iteration $(\mathrm{m}+1)$,

$\{x\}^{(m)}-$ vector of unknowns at iteration (m),

$[\mathrm{J}]^{-1}$ - the Jacobian inverse matrix of system,

$\{F\}_{0}$-vector of values equations $\mathrm{F}$ calculated with the estimated initial flow rates.

\section{THE PARTICULARITIES OF THE METHOD IN THE PRESENCE OF PRV}

When installing a PRV (Fig. 2a) an energy jump occurs in this device. If it is a spring it consumes energy to set the opening of the PRV. In the literature, for example [5], it is recommended to replace PRV with a fictitious tank where the free surface elevation is equal to the sum of the piezometric head at which the PRV is set and the elevation of the point where the PRV is mounted in the network (Fig.2b) . The Law of Energy Conservation for the pseudo-loop I is written as:

$$
H_{1}-H_{V R P}=h_{f R J}+h_{f J K}-h_{f K S}
$$

where:

$\mathrm{H}_{1}$ - elevation of liquid level in the tank 1 ,
$\mathrm{H}_{\mathrm{VRP}}$ elevation of liquid level in the fictitious tank replacing VRP,

$\mathrm{h}_{\mathrm{fRJ}}$ - head loss on the pipe $\mathrm{RJ}$,

$\mathrm{h}_{\mathrm{fJK}} \mathrm{H}^{-}$head loss on the pipe $\mathrm{JK}$,

$\mathrm{h}_{\mathrm{fKS}}-$ head loss on the pipe $\mathrm{KS}$.

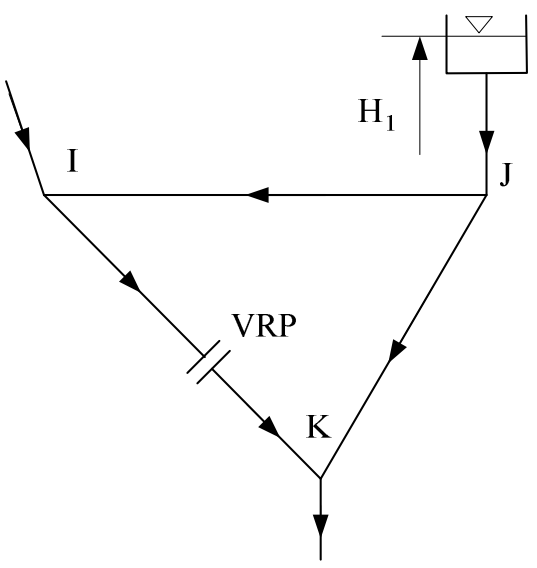

Fig.2a The network with PRV

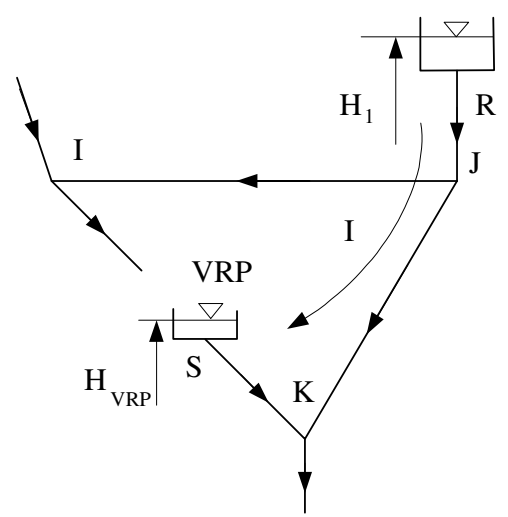

Fig.2b The modified network containing the fictitious tank

To solve a network containing PRV, the method outlined above involves the following steps:

1. Write the continuity equation in junctions ignoring PRV .

2. Replace PRV with a fictitious tank having the free surface elevation equal to the sum of the elevation of the point where the PRV is 
mounted and the pressure head corresponding to the load set for the PRV.

3. Write the system of equations comprising the mass continuity equations in the junctions (nodes) and the energy conservation equations on loops and pseudo-loops for the modified network.

\section{PIPELINE NETWORK APPLICATION COMPRISING PRV}

The above procedure is applied to the six-pipe network of water (Fig. 3) and in which the pressure reduction valve (PRV) is mounted on the pipe (6) at a distance of 15 [m] downstream of the node [1].

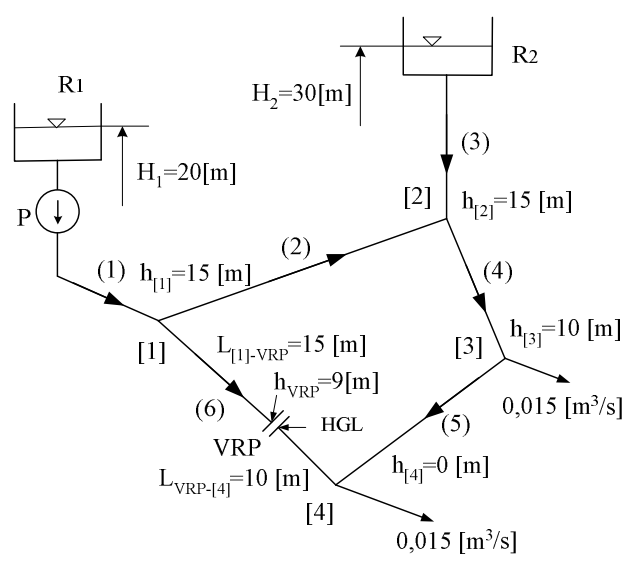

Fig.3 The network on which PRV is mounted

Note the pipe number between round brackets, for example (1) and the node number between square brackets, for example [1]. The network comprising the tank $\mathrm{R}_{1}$ having the elevation $\mathrm{H}_{1}=20[\mathrm{~m}]$, the tank $\mathrm{R}_{2}$ having the elevation $\mathrm{H}_{2}=30[\mathrm{~m}]$ and the centrifugal pump $\mathrm{P}$ having the characteristic $\mathrm{h}_{\mathrm{P}}=24 \mathrm{Q}^{2}$ $5 \mathrm{Q}+35$. The PRV is set to reduce the pressure head downstream of it at value 19.1 [m] water column $(187,180 \mathrm{Kpa})$. The pipes are made of steel with roughness $\mathrm{k}=0,00003$ [m]. The dimensions presented in (Table 1) are: $\mathrm{Q}_{0}$-estimated initial flow (NewtonRaphson method is iterative method), k- roughness of pipes, D-inner pipe diameter, erelative roughness, L- length of pipes, v-fluid circulation velocity, Re-Reynolds number, $\lambda$ friction coefficient at fluid flow, $\alpha$ hydrodynamic characteristic of the pipe (Ec.5), $\mathrm{h}_{[\mathrm{i}]}$-elevation of point [i].

Tab.1 Network Parameters

\begin{tabular}{|c|c|c|c|c|c|}
\hline $\begin{array}{c}\text { Nr. } \\
\text { pipe }\end{array}$ & \begin{tabular}{c}
1 \\
\cline { 2 - 6 } \\
{$\left[\mathrm{m}^{3} / \mathrm{h}\right]$}
\end{tabular} & $\begin{array}{c}\mathrm{Q}_{0} \\
{\left[\mathrm{~m}^{3} / \mathrm{s}\right]}\end{array}$ & $\mathrm{k}[\mathrm{m}]$ & $\mathrm{D}[\mathrm{m}]$ & $\mathrm{e} \cdot \mathrm{E} 04$ \\
\hline 1 & 54 & 0,015 & $3 \mathrm{E}-5$ & 0,104 & 2,88 \\
\hline 2 & 18 & 0,005 & $3 \mathrm{E}-5$ & 0,06 & 5,01 \\
\hline 3 & 54 & 0,015 & $3 \mathrm{E}-5$ & 0,104 & 2,88 \\
\hline 4 & 72 & 0,02 & $3 \mathrm{E}-5$ & 0,104 & 2,88 \\
\hline 5 & 18 & 0,005 & $3 \mathrm{E}-5$ & 0,104 & 2,88 \\
\hline 6 & 36 & 0,01 & $3 \mathrm{E}-5$ & 0,060 & 5.01 \\
\hline
\end{tabular}

Tab.1 (continuation)

\begin{tabular}{|c|c|c|c|}
\hline \multirow{2}{*}{$\begin{array}{c}\text { Nr. } \\
\text { pipe }\end{array}$} & 7 & 8 & 9 \\
\cline { 2 - 4 } & $\mathrm{L}[\mathrm{m}]$ & $\mathrm{v}[\mathrm{m} / \mathrm{s}]$ & $\mathrm{Re}$ \\
\hline 1 & 30 & 1,766 & 182275,3 \\
\hline 2 & 40 & 3,538 & 210629,2 \\
\hline 3 & 10 & 1,766 & 182275,3 \\
\hline 4 & 15 & 2,355 & 243033,7 \\
\hline 5 & 25 & 0,588 & 60758,42 \\
\hline 6 & 25 & 3,538 & 210629,2 \\
\hline
\end{tabular}

Tab.1 (continuation)

\begin{tabular}{|c|c|c|}
\hline 10 & 11 & 12 \\
\hline$\lambda$ & ${\mathrm{a}\left[\mathrm{s}^{2} / \mathrm{m}^{5}\right]}_{1}$ & $\mathrm{~h}_{[\mathrm{i}]}[\mathrm{m}]$ \\
\hline 0,01572 & 1603,006 & $\mathrm{~h}_{[1]}=15$ \\
\hline 0,01745 & 37139,25 & $\mathrm{~h}_{[2]}=15$ \\
\hline 0,01572 & 534,335 & $\mathrm{~h}_{[3]}=10$ \\
\hline 0,014895 & 759,430 & $\mathrm{~h}_{[4]}=0$ \\
\hline 0,020153 & 1712,536 & $\mathrm{~h}_{[\mathrm{VRP}]}=9$ \\
\hline 0,015298 & 20340,13 & \\
\hline
\end{tabular}

The system of Q-equations for this network comprise four equations of junction continuity and two energy conservation equations on the two pseudo-loops. Continuity equations are not affected by PRV presence and have the form: 
Node [1], $F_{1}=0 \rightarrow Q_{1}-Q_{2}-Q_{6}=0$

Node [2], $F_{2}=0 \rightarrow Q_{3}+Q_{2}-Q_{4}=0$

Node [3], $F_{3}=0 \rightarrow Q_{4}-Q_{5}-0,015=0$

Node [4], $F_{4}=0 \rightarrow Q_{6}+Q_{5}-0,015=0$

where:

$\mathrm{Q}_{1}, \mathrm{Q}_{2} \ldots \mathrm{Q}_{6}$ are flows in the pipes (1), (2)...(6).

In order to write energy conservation equations, the network in (Fig.3) is changed, the PRV is removed and replaced by a free surface reservoir at a elevation equal to the pressure head at which the PRV is set plus the elevation of the point where the PRV is mounted in the network $(\mathrm{HGL}=28.1[\mathrm{~m}])$.

The elevation of the point PRV $\left(\mathrm{h}_{[\mathrm{PRV}]}\right)$ is obtained from the triangles achieved by the elevations of the points [1] and [4] and the lengths of the pipe sections (6) between the node [1] and the VRP and VRP and node [4].

$$
\frac{15}{25}=\frac{x}{15} \rightarrow h_{[P R V]}=9[\mathrm{~m}]
$$

The modified network shown in (Fig.4) comprises two pseudo-loops.

The energy conservation equation for the pseudo loop I, in which the losses are calculated with the relations (4), has the form:

$$
\begin{aligned}
& F_{5}=0 \rightarrow H_{2}-h_{P}-H_{1}= \\
& =a_{3} \cdot Q_{3}^{2}-a_{2} \cdot Q_{2}^{2}-a_{1} \cdot Q_{1}^{2}
\end{aligned}
$$

The energy conservation pseudoloop II, in which the losses are calculated with the relations (4), has the form:

$$
\begin{aligned}
& F_{6}=0 \rightarrow H_{2}-H_{V R P}= \\
& =a_{3} \cdot Q_{3}^{2}+a_{4} \cdot Q_{4}^{4}+a_{5} \cdot Q_{5}^{2}-a_{6}^{\prime} \cdot Q_{6}^{2}
\end{aligned}
$$

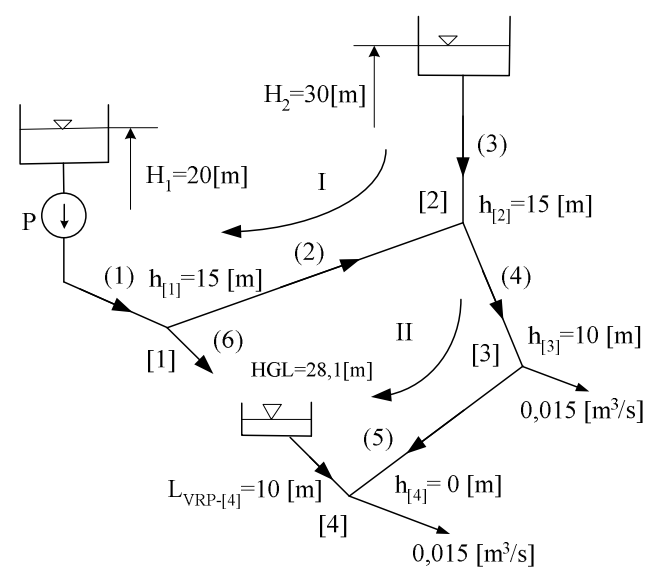

Fig. 4 Modified network layout

The coefficient $a_{6}^{\prime}$ corresponds to the pipe section between PRV and the node [4] (which the fluid circulates in pseudo-loop II). It is calculated as a fraction of the coefficient, proportional to the ratio of the pipe length between the PRV and the node [4] and the total length of the pipe to which the PRV is mounted.

$$
a_{6}^{\prime}=a_{6} \cdot \frac{L_{V R P-[4]}}{L_{6}}=20340.13 \cdot \frac{10}{25}=8136
$$

The system of equations accomplished by the equations (10), (11) and (12) written in canonical form with the values of the coefficients $a_{1} \ldots a_{6}$ (see Table 1 ) for the first iteration becomes:

$$
\begin{aligned}
& F_{1}=0 \rightarrow Q_{1}-Q_{2}-Q_{6}=0 \\
& F_{2}=0 \rightarrow Q_{3}+Q_{2}-Q_{4}=0 \\
& F_{3}=0 \rightarrow Q_{4}-Q_{5}-0,015=0 \\
& F_{4}=0 \rightarrow Q_{6}+Q_{5}-0,015=0 \\
& F_{5}=0 \rightarrow 30-24 \cdot Q_{1}^{2}+5 \cdot Q_{1}-35-20- \\
& -534,3 \cdot Q_{3}^{2}+37139,25 \cdot Q_{2}^{2}++1603,06 \cdot Q_{1}^{2}=0 \\
& F_{6}=0 \rightarrow 30-28,1-534,335 \cdot Q_{3}^{2}- \\
& -759,43 \cdot Q_{4}^{4}--1712,536 \cdot Q_{5}^{2}+8136 \cdot Q_{6}^{2}=0
\end{aligned}
$$


The system (14) is a determined system containing six equations with six unknowns represented by the flows $\mathrm{Q}_{1}, \mathrm{Q}_{2} \ldots \mathrm{Q}_{6}$. It is solved by the Newton-Raphson method. After six iterations, the convergence was achieved, $\left|\mathrm{Q}_{5}-\mathrm{Q}_{6}\right| \leq 0,0005[\mathrm{~m} 3 / \mathrm{s}]$. The coefficients $a_{1} \ldots a_{6}$ are calculated after each iteration as the flow regime changes.

For the first iteration the values of Newton-Raphson components are:

$$
\{F\}_{0}=\left\{\begin{array}{lllll}
0 & 0 & 0 & -3,76 & 2,24
\end{array}\right\}^{T}
$$

$$
[J]=
$$

$\begin{array}{|ccc|}1 & -1 & 0 \\ 0 & 1 & 1 \\ 0 & 0 & 0 \\ 0 & 0 & 0 \\ 52,37 & 74278 & -16,0299 \\ 0 & 0 & -16,0299 \\ 0 & & \\ 0 & 0 & -1 \\ -1 & 0 & 0 \\ 1 & -1 & 0 \\ 0 & 1 & 1 \\ 0 & 0 & 0 \\ -30,3772 & -17,125 & 162,72\end{array}$

$$
\left[J_{(0)}\right]^{-1}=
$$

$\begin{array}{cc}0,999345 & 0,0709894 \\ -0,0007 & 0,0001504 \\ 0,000655 & 0,92901050 \\ -5 \mathrm{E}-05 & -0,070839 \\ -5 \mathrm{E}-05 & -0,070839 \\ 0,010964 & 0,2054747\end{array}$

0,205137

2,69E-05

0,794863

0,79489

0,20511

0,580449

(16)

$\begin{array}{ccc}0,951941 & 0,0019015 & 0,007318 \\ -0,05026 & 0,002419106 & -0,00093 \\ 0,048059 & -0,00190155 & -0,00732 \\ -0,0022 & 0,000517551 & -0,00825 \\ -0,0022 & 0,00051755 & -0,00825 \\ 1,002201 & -0,00051755 & 0,008248\end{array}$

(17)

$$
\begin{aligned}
& {\left[J_{(0)}\right]^{-1} x\{F\}_{0}=} \\
& =\{0,0150,0050,0150,020,0050,01\}^{T} \\
& \{x\}^{(0)}=\left\{\begin{array}{lllll}
5,1 & 5,06 & 24,8 & 29,9 & 14,9
\end{array}\right. \\
& 6,53 E-2\}^{T} x E-3
\end{aligned}
$$

The values of the flows corresponding to the six pipes obtained in the six iterations are presented in (Table 2).

Tab.2 Flow values in the six iterations

\begin{tabular}{|c|c|c|c|}
\hline \multirow{2}{*}{ Nr.pipe } & \multicolumn{3}{|c|}{$\mathrm{Q}\left[\mathrm{m}^{3} / \mathrm{s}\right]$} \\
\cline { 2 - 4 } & Iteration 1 & Iteration 2 & Iteration 3 \\
\hline 1 & 0,005125 & 0,004499 & 0,021497 \\
\hline 2 & 0,00506 & 0,003311 & 0,019968 \\
\hline 3 & 0,024875 & 0,025501 & 0,008503 \\
\hline 4 & 0,029935 & 0,028812 & 0,028471 \\
\hline 5 & 0,014935 & 0,013812 & 0,013471 \\
\hline 6 & $6,53 \mathrm{E}-05$ & 0,001188 & 0,001529 \\
\hline
\end{tabular}

Tab.2 (continuation)

\begin{tabular}{|c|c|c|}
\hline \multicolumn{3}{|c|}{$\mathrm{Q}\left[\mathrm{m}^{3} / \mathrm{s}\right]$} \\
\hline Iteration 4 & Iteration 5 & Iteration 6 \\
\hline 0,01727 & 0,015703 & 0,015868 \\
\hline 0,01305 & 0,011316 & 0,011166 \\
\hline 0,01273 & 0,014297 & 0,014132 \\
\hline 0,02578 & 0,025613 & 0,025298 \\
\hline 0,01078 & 0,010613 & 0,010298 \\
\hline 0,00422 & 0,004387 & 0,004702 \\
\hline
\end{tabular}

Knowing the flows in each pipe Q1 ... Q6 can be calculated the energy head in each node with relation (6).

\section{CONCLUSIONS}

The introduction of the fictitious tank instead of the PRV allows the energy conservation equation to be written in a loop or pseudo-loop despite the energy leap in the PRV. With mass conservation equations and energy conservation equations, the NewtonRaphson piping network can be solved. 
Using the fictitious tank, it is possible to estimate how PRV works. In the application of paragraph 3 to see how PRV works, compare the pressure head before PRV with pressure head it is set. For this purpose, the energy head is calculated in the node [1].

$H_{[1]}=H_{1}+h_{P}-a_{1} \cdot Q_{1}^{2}=20+24 \cdot Q_{1}^{2}-$

$-5 \cdot Q_{1}+35-0,403=34,52[\mathrm{~m}]$

where:

$\mathrm{H}_{[1]}$-energy head of node [1],

$\mathrm{H}_{1}$ - energy head of tank 1 ,

$\mathrm{h}_{\mathrm{P}}$-pump head,

$a_{1} \cdot Q_{1}^{2}$-head losses pipe (1),

$a_{1}$ - hydrodynamic coefficient pipe (1),

$\mathrm{Q}_{1}$-flow pipe (1) (see Tab.2, iteration 6).

The energy head before the PRV, from the network conditions, is calculated with the relation:

$$
\begin{aligned}
& H_{[A P R V]}=H_{[1]}-a_{6}^{\prime \prime} \cdot Q_{6}^{2}= \\
& 34,523[m]-0,269[m]=34,254[m]
\end{aligned}
$$

where:

$\mathrm{H}_{[\mathrm{APRV}]}$ - the energy head before PRV,

$\mathrm{H}_{[1]^{-}}$the energy head of node [1],

$a_{6}^{\prime \prime} \cdot Q_{6}^{2}$ - head loss on the section between the node [1] and PRV,

$\mathrm{Q}_{6-}$ pipe flow (6).

Head loss on the section between node [1] and PRV, calculated on the basis of the relation (4), have the value:

$$
\begin{aligned}
& a_{6}^{\prime \prime} \cdot Q^{2}{ }_{6}=a_{6} \cdot \frac{L_{[1]-P R V}}{L_{6}} \cdot Q_{6}^{2}= \\
& =20340,13 \cdot \frac{15}{25} \cdot 0,0158^{2}=0,269[\mathrm{~m}]
\end{aligned}
$$

where: $a_{6}^{\prime \prime}$ - the hydrodynamic coefficient of the pipe section comprised between node [1] and PRV,

$\mathrm{Q}_{6}$ - pipe flow (6),

$a_{6}$ - the hydrodynamic coefficient of pipe (6).

The hydrodynamic coefficient corresponding to the pipe section between node [1] and PRV, $a_{6}^{\prime \prime}$ represents a fraction of the hydrodynamic coefficient of the pipe (6) and is calculated with the relation:

$$
\begin{aligned}
& a_{\mathbf{6}}^{\prime \prime}=a_{6} \cdot \frac{L_{[1]-P R V}}{L_{6}}= \\
& =20340,13 \cdot \frac{15}{25}=12204\left[\mathrm{~s}^{2} / \mathrm{m}^{5}\right]
\end{aligned}
$$

where:

$a_{6}^{\prime \prime}$ - the hydrodynamic coefficient of the pipe section comprised between node [1] and PRV, PRV,

$\mathrm{L}_{[1]-\mathrm{PRV}^{-}}$the length between node [1] and

From Bernoulli's equation, the energy head has three components, the pressure head that corresponds to static pressure, elevation and kinetic head. The pressure head and elevation compose piezometric head. To see the operating mode of the pressure reduction valve (PRV) must be compared the pressure head before PRV with the value PRV it is set.

$$
\begin{aligned}
& \frac{p}{\gamma}=H_{[A P R V]}-h_{[P R V]}-\frac{v_{6}^{2}}{2 g}= \\
& =34,254[\mathrm{~m}]-9[\mathrm{~m}]-0,638[\mathrm{~m}]=24,615[\mathrm{~m}]
\end{aligned}
$$

where:

$$
\frac{p}{\gamma} \text { - the pressure head at the point where }
$$

PRV is mounted,

$$
\left.H_{[A P R V}\right]^{-} \text {the energy head where the }
$$

PRV is mounted, 
$\frac{v_{6}^{2}}{2 g}$ - the kinetic head where the PRV is mounted,

$\mathrm{v}_{6}$ - water velocity in the pipe (6),

g- gravity acceleration.

The surface elevation of the fictitious tank that replaces the PRV $(\mathrm{HGL}=28,1[\mathrm{~m}]$ contains two components, the pressure head it is set PRV and elevation of the point where the $P R V$ is mounted in the network.

$$
\begin{aligned}
& H G L=\left(\frac{p}{\gamma}\right)_{s e t}+h_{[P R V]} \rightarrow\left(\frac{p}{\gamma}\right)_{s e t}= \\
& =H G L-h_{[P R V]}=28,1[m]-9[m]=19,1[\mathrm{~m}]
\end{aligned}
$$

where:

$$
\begin{aligned}
& \left(\frac{p}{\gamma}\right)_{s e t} \text { - the pressure head it is set, } \\
& h_{P R V]} \text {-elevation of the point where the }
\end{aligned}
$$

PRV is mounted,

HGL- elevation of the fictitious tank.

It is noted the PRV pressure head is 24,615 [m] water column (Ec.19), higher than the pressure head at which the PRV it is set, 19.1 [m] water column (Ec.20). Under these conditions, the pressure reduction valve (PRV) operates in normal mode (reduces the pressure from $241227 \mathrm{Kpa}$, corresponding to 24,615 [m] water column to $187,180 \mathrm{Kpa}$, corresponding to $19,1[\mathrm{~m}]$ water column.

When a pipeline network contains a BPV (Back pressure valve), a similar method is applied having steps:

1. Write the continuity equation in junctions ignoring BPV .

2. Replace PRV with a fictitious tank having the free surface elevation equal to the sum of the elevation of the point where the BPV is mounted and the pressure head the pressure it has to maintain in the system. The pipe sec- tion downstream of the BPV, from BPV to the first junction is removed

3.Write the system of equations comprising the mass continuity equations in the junctions (nodes) and the energy conservation equations on loops and pseudo-loops for the modified network.

\section{REFERENCES}

[1]Anton V., Popoviciu M., Fitero I., "Hidraulică şi mașini hidraulice”, Editura Didactica şi Pedagogica, București 1978

[2] Collins M., "Solving the Pipe Network Analysis Problem Using Optimization Techniques", School of Engineering and Aplies Science, Southern Methodist University, Dallas 1977

[3].Epp, R. and Fowler, A., "Efficient code for steady-state flows in networks", Journal of Hydraulics Division, Proceedings of the ASCE 96 (HY1), 1970

[4].Ioan, A., "The Application of Simultaneous Loop Equation Solution for Ship Networks ", The Annals of "Dunarea de Jos" University of Galati, Fascicle XI Shipbuilding, ISSN 1221-4620, 2015

[5].Jeppson, R., "Steady Flow Analysis Pipe Networks ", An Instructional Manuals, Utah State University, 1984.

[6].Lambert, M., Mariam, T., Susan, F., "Pipe Network Analysis", VDM Publishing, ISBN 6131288151, 2010.

[7].Larock, B., Jeppson, R., Watters, G., " $H y$ draulics of Pipeline Systems”, CRC Press, ISBN 0-8493-1906-8, pp 43-96 New York, 2000.

[8].Mun-Fong L., "Pipe Network Analysis", Publication No.77 University of Florida Gainesville, 1983.

[9].Prabhata, K.S., Ashok, K.S., "Design of Water Supply Networks ”, John Wiley \& Ons Inc. , Online ISBN 9780470225059, New York, 2008.

[10].Pramond, R.B., "Analysis of Flow in Water Distribution Networks", Technomic Pub. Co. , University of Michigan, 2007.

[11]White M. F., "Fluid Mechanics", Mc.GrawHill Series in Mechanical Engineering, ISBN 9780077422417

[12].Wood, D.J. and Charles O.A.. „Hydraulic network analysis using linear theory", Journal of Hydraulic Division, ASCE HY7,1972

Paper received on December $1^{\text {th }}, 2018$ 